\title{
Recent advances in the analysis of TBBPA/TBBPS, TBBPA/TBBPS derivatives and their transformation products
}

\author{
Guangbo Qu, Aifeng Liu, Ligang Hu, Sijin Liu *, Jianbo Shi *, Guibin Jiang \\ State Key Laboratory of Environmental Chemistry and Ecotoxicology, Research Center for Eco-Environmental Sciences, Chinese Academy of Sciences, Beijing \\ 100085, China
}

\section{A R T I C L E I N F O}

\section{Keywords:}

Brominated flame retardant

Emerging

By-product

Chromatography

Mass spectrometry

Tetrabromobisphenol A

Tetrabromobisphenol A derivatives

Tetrabromobisphenol S

Tetrabromobisphenol S derivatives

Transformation

\begin{abstract}
A B S T R A C T
Tetrabromobisphenol A (TBBPA) is the most widely used brominated flame retardant. TBBPA and its alternative, tetrabromobisphenol S (TBBPS), are the reactive chemicals used to produce TBBPA/S derivatives. The manufacturing and application of TBBPA/S derivatives may result in their accumulation in environmental compartments and may cause risks to environmental safety and human health. To investigate the occurrence and transformation products of TBBPA/S and TBBPA/S derivatives, it is imperative to develop effective sample preparation and sensitive analytical methods for various environmental matrices. In this paper, we summarize the techniques for analysis of TBBPA/S and their derivatives. We also critically review methodologies for the identification of unknown metabolites transformed from these chemicals. In the perspective section, we discuss trends in analytical strategies for studying emerging TBBPA/S derivatives. (C) 2016 Elsevier B.V. All rights reserved.
\end{abstract}

\section{Contents}

1. Introduction 15

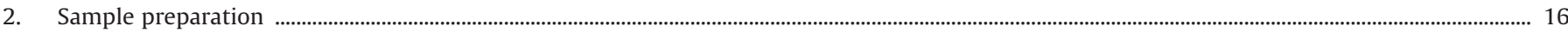

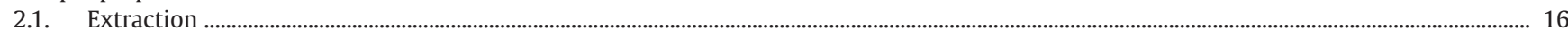

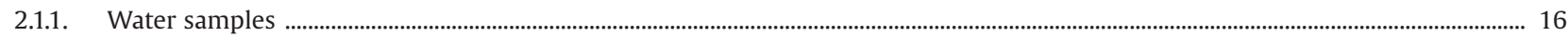

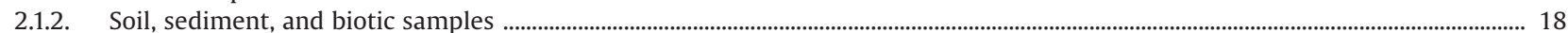

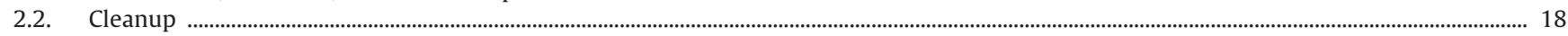

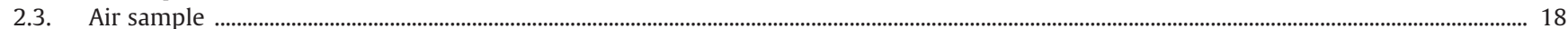

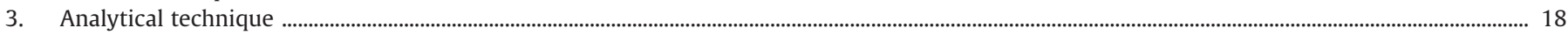

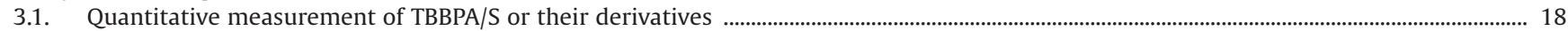

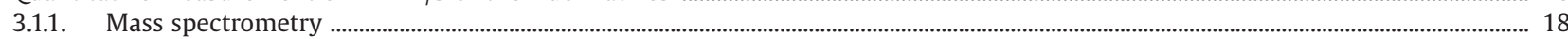

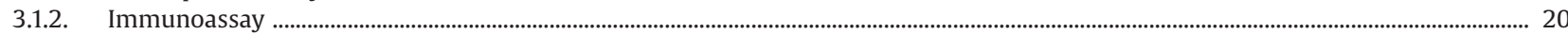

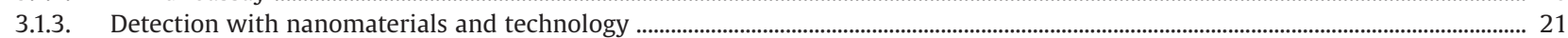

3.2. Transformation product characterization ................................................................................................................................................................. 21

3.2.1. $\quad$ MS for molecular structure elucidation ........................................................................................................................................................ 21

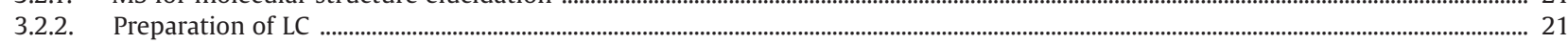

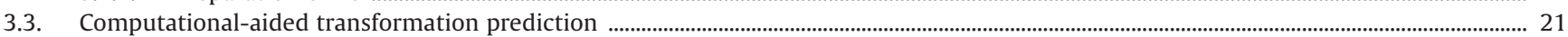

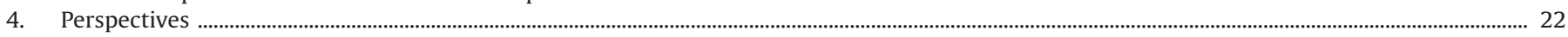

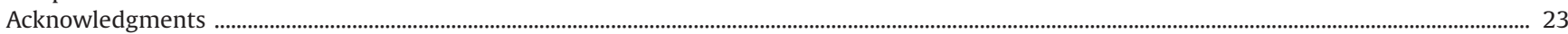

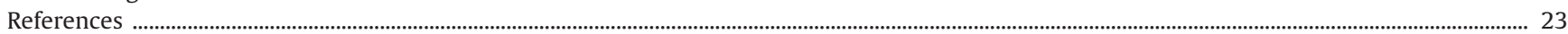

Abbreviations: APPI, atmospheric pressure photoionization; APCI, atmospheric pressure chemical ionization; ASE, accelerated solvent extraction; ELISA, enzyme-linked

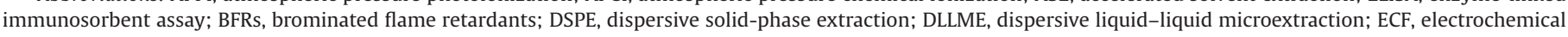

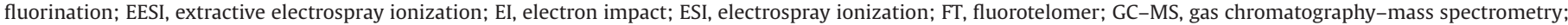

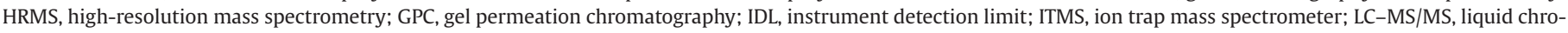

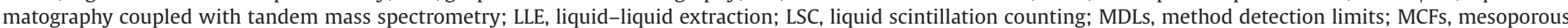

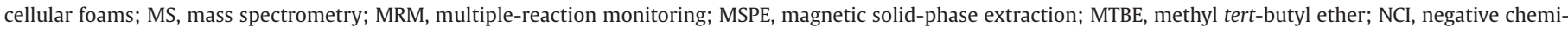

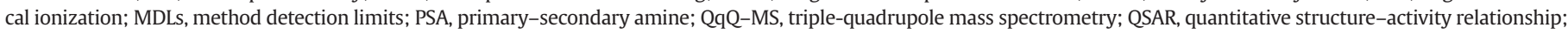
SERS, surface-enhanced Raman scattering; SPE, solid-phase extraction; TOF, time of flight; TRFIA, time-resolved fluoroimmunoassay.

* Corresponding authors. Tel.: +86-010-62849129; Fax: +86-010-62849339.

E-mail addresses: sjliu@rcees.ac.cn (S. Liu), jbshi@rcees.ac.cn (J. Shi). 


\section{Introduction}

The most widely used brominated flame retardant (BFR), tetrabromobisphenol A (TBBPA), is frequently being used in plastics, textiles, and electronics [1]. TBBPA and its alternative, tetrabromobisphenol $\mathrm{S}$ (TBBPS), are the reactive chemicals used to produce TBBPA/S derivatives, via modification of the TBBPA/S hydroxyl groups. These derivatives can be added in polymer products or selected as precursor compounds for a series of other TBBPAbased polymers $[2,3]$. The contamination of TBBPA/S and TBBPA/S derivatives in the environmental matrices leads to potential environmental and health risks. Studies on toxicity evaluation have indicated the potential adverse effects of these chemicals on mammals and aquatic organisms [4], while the transformation of TBBPA in the environment may alter their potential biological effects due to their transformation products [5,6]. TBBPA/S derivatives discussed in the current review were summarized in Fig. 1. The first group of TBBPA derivatives developed for industrial application was synthesized using TBBPA/S as a raw material with the two phenolic hydroxyl groups modified. Here, these chemicals are referred to

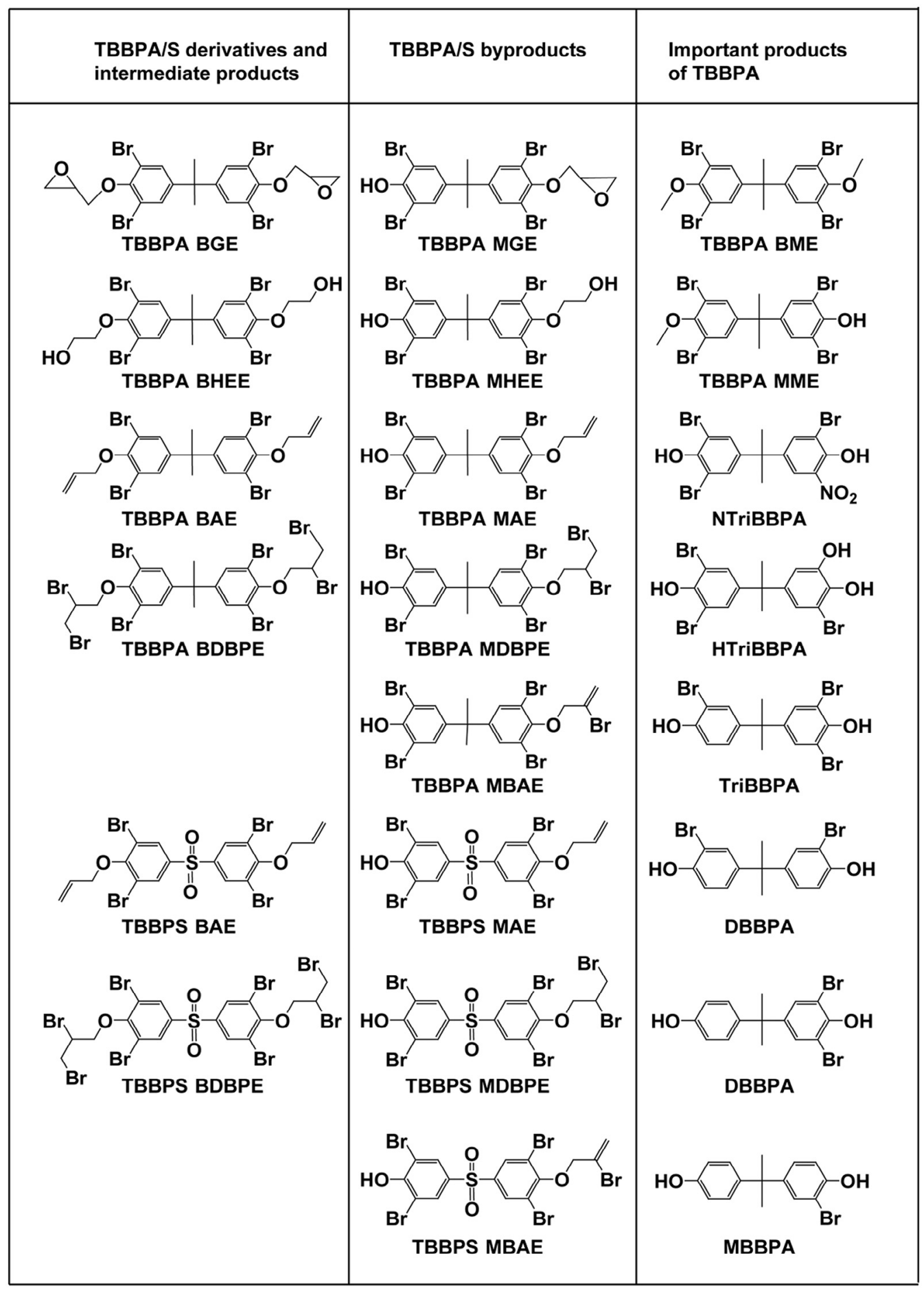

Fig. 1. Chemical structures of important TBBPA/S derivatives. 
as the main TBBPA/S derivatives (MTDs). The second group contains by-products of MTDs with one exposed phenolic hydroxyl group that are formed unintentionally during the process of manufacturing the main product [7]. The representative chemicals of this group are TBBPA mono(allyl ether) (TBBPA MAE) and TBBPA mono(2,3dibromopropyl ether) (TBBPA MDBPE) that can be generated as a result of the incomplete formation of both ether bonds (Fig. 1). The third group contains the transformation products of TBBPA/S and MTDs. For instance, TBBPA bis(methyl ether) (TBBPA BME) and TBBPA mono(methyl ether) (TBBPA MME) are the resultant transformation products of TBBPA via aerobic metabolism by bacteria [8]. Some products, such as TBBPA glucoside, could be formed as the result of biological transformation through the combination of TBBPA with biological molecules [9]. As some mono-modified TBBPAs can be formed due to the transformation of MTDs, these derivatives are created either by the transformation of MTDs or by the generation of by-products during manufacturing.

A wide spectrum of TBBPA derivatives has been detected in the environment. Some MTDs have been identified in the environmental samples at higher levels than other derivatives [7,10]. TBBPA bis(allyl) ether (TBBPA BAE) and TBBPA/S bis(2,3-dibromopropyl ether) (TBBPA BDBPE) have been found in the biological samples, including herring gulls and mollusks [2,3,10]. The by-products of MTDs have also been identified in recent years in various environmental samples. Since the determination of TBBPA BAE and TBBPA BDBPE in MTD products, these forms of mono-modified TBBPA/S derivatives were identified in the environmental samples sequentially. For instance, TBBPA mono(2-hydroxyethyl ether) (TBBPA MHEE) and TBBPA mono(glycidyl ether) (TBBPA MGE) were identified in water samples collected around a manufacturing plant [10]. MTDs, including TBBPS bis(2,3-dibromopropyl ether) (TBBPS BDBPE), and by-products or transformation products such as TBBPS mono(allyl ether) (TBBPS MAE), TBBPS mono(2-bromoallyl ether) (TBBPS MBAE), and TBBPS mono(2,3-dibromopropyl ether) (TBBPS MDBPE), have been detected in mollusks [11].

To evaluate the potential effect on these BFRs on environmental health, it is first necessary to define their distribution and transportation characteristics. To this end, there has been an increasing focus on analytical methods for MTD and TBBPA/S determination. A recent trend is the development of mass spectrometry (MS) techniques [3,7,10-12], including the application of liquid chromatography coupled with MS (LC-MS) and gas chromatography coupled with MS (GC-MS) in the analysis of TBBPA BAE, TBBPA/S BDBPE and their by-products. However, GC may not be the best tool. For instance, MTDs tend to degrade thermally when using GC-MS, and thus, this approach fails to explain the target chemicals with the obtained clusters [3]. Although LC-MS might be a better option for TBBPA derivative analysis, the poor efficiency of ionization for certain MTDs continues to be a concern for nonpolar chemical analysis $[3,10]$. TBBPA MAE, TBBPA MDBPE, and TBBPA MHEE, for example, have been found in environmental samples as novel brominated substances using LC-coupled tandem MS (LCMS/MS) and LC coupled with Orbitrap mass spectrometry [7,10,11].

Detailed characterization of the unknown metabolites generated by TBBPA/S and their derivatives is required for elucidating the pathways responsible for transformation of TBBPA/S and MTDs [13]. Cumulative evidence suggests that abiotic degradation, including photolysis, oxidation, reduction, and radical reactions, are involved in TBBPA degradation [14-16]. As compared with abiotic reactions, biotic reactions are considered to be the main transformation pathways of TBBPA and can result in the presence of unknown brominated substances in environmental compartments $[8,17,18]$. With the development of analytical methods based on MS, various transformation products of TBBPA have been observed [8,9,15-21]. However, there has been little or no documented investigation concerning the degradation of TBBPA derivatives.
As sample pretreatment can effectively remove matrix effects and purify and concentrate target pollutants, sample preparation methods have been optimized for TBBPA derivative analysis. Given the widely varying properties of TBBPA derivatives, pretreatment is highly dependent on the type of target chemicals and sample properties [10]. Methods such as accelerated solvent extraction (ASE), liquidliquid extraction (LLE), and sonication-assisted extraction have proven effective for the extraction of TBBPA/S derivatives [13,22]. There are a number of approaches using nanomaterials that can significantly increase the efficiency of extraction and impurity elimination. However, improvements in sample preparation are still needed to achieve high specificity and sensitivity. Another trend is the development of novel analytical approaches for the analysis of TBBPA/S and their derivatives. Apart from MS, other techniques that can be applied to TBBPA detection include molecular imprinting, nanotechnology, surface-enhanced Raman scattering (SERS), and immunoassay [23-25].

Improvement in the analytical approaches for detecting TBBPA derivatives is warranted, in both terms of analytical techniques and sample preparation. The aims of this review are 1) to discuss the extraction and purification strategies of target TBBPA/S and their derivatives; 2 ) to present the recent progress and trends related to the analysis of TBBPA/S and their derivatives; 3 ) to discuss the strategies for identifying unknown TBBPA derivatives in the environment or under laboratory exposure conditions; and 4) to give perspectives for future studies of TBBPA/S and their derivatives.

\section{Sample preparation}

The effective extraction and cleanup of pollutant analysis in the environmental samples would improve the detection sensitivity and decrease matrix effects. Simultaneous pretreatment is still an obstacle for all the TBBPA/S derivatives to investigate their environmental behavior study. Sample preparation of TBBPA has been summarized in the previous reviews [2,13]. Thus, this review will highlight novel pretreatment methods for TBBPA and applied sample preparation methods for derivatives (Table 1 ).

\subsection{Extraction}

\subsubsection{Water samples}

2.1.1.1. Liquid-liquid extraction. LLE is a common method for extracting TBBPA/S and their derivatives [7,10,11]. The presence of phenol in an aqueous solution may be affected by the $\mathrm{pH}$ value. For example, phenols are liable to participate in the organic phase when they are extracted from an acidic solution [26]. Good recoveries ranging from $59 \%$ to $101 \%$ - were obtained when the $\mathrm{pH}$ value was adjusted to four to five with the dichloromethane (DCM) before extraction for TBBPA MHEE and TBBPA MGE [10].

2.1.1.2. Solid-phase extraction. For optimization of solid-phase extraction (SPE) procedures to concentrate TBBPA/S derivatives from river water, tap water, and pure water, three SPE adsorbents were tested: Oasis HLB (Waters, MA, USA), LC-18 (alkyl-bonded phase), and Carbograph-1 cartridges. Carbograph-1 cartridge showed recoveries $>70 \%$ with good repeatability $[27,28]$. Meanwhile, the combination of LC-C18 cartridges with LC-Si SPE cartridges for the extraction of TBBPA and less-brominated BPA from sewage sludge led to recoveries ranging from $75 \%$ to $105 \%$ [29]. The pH value of water samples should be considered, and the best recoveries were obtained when the $\mathrm{pH}$ of the sample was two units below the lowest $p K_{a}$ of the analyzed TBBPA and their derivatives [30]. For the cleanup of nonwater samples, the most widely used methods were gel permeation chromatography (GPC), activated silica gel column, and Florisil [6,31]. Commercially available SPE tubes also have good applicability for the cleanup of residues extracted from soil, sediment, 
Representative analytical procedures used for determining TBBPA/S derivatives in environmental matrices

\begin{tabular}{|c|c|c|c|c|c|c|c|c|c|}
\hline Sample type & Compounds & Pretreatment & Extraction & Cleanup & Instrumental analysis & $\begin{array}{l}\text { Recovery } \\
(\%)\end{array}$ & $\mathrm{SD}(\%)$ & $\begin{array}{l}\mathrm{LOD}^{\mathrm{a}}(\mathrm{ng} / \mathrm{g} \\
\left.\mathrm{ng} / \mathrm{L}, \mathrm{pg} / \mathrm{m}^{3}\right)\end{array}$ & References \\
\hline \multicolumn{10}{|l|}{ Liquid sample } \\
\hline Culture solution & TBBPA degradation products & $\mathrm{N}$ & LLE & SPE-HLB & HPLC-ESI-MS/MS & $\mathrm{N}$ & $\mathrm{N}$ & $\mathrm{N}$ & [9] \\
\hline $\begin{array}{l}\text { River water, tap water, } \\
\text { and waste water }\end{array}$ & TBBPA MHEE, TBBPA MGE & Filtration & LLE & $\mathrm{N}$ & Orbitrap-HRMS & $59-101$ & $5-17$ & $0.9,0.8$ & [10] \\
\hline River water & TВBPA ВAE & Filtration & LLE & $\mathrm{N}$ & HPLC-APCI-MS/MS & $\mathrm{N}$ & $\mathrm{N}$ & $\mathrm{N}$ & [12] \\
\hline $\begin{array}{l}\text { Water reaction } \\
\text { solution }\end{array}$ & TBBPA oxidation products & $\begin{array}{l}\text { Quenched with } \\
\text { hydroxylamine }\end{array}$ & - & $\mathrm{N}$ & HPLC-ESI-MS/MS & $\mathrm{N}$ & $\mathrm{N}$ & $\mathrm{N}$ & [15] \\
\hline Water & TBBPA degradation products & $\mathrm{N}$ & SPE-C18 cartridges & $\mathrm{N}$ & $\begin{array}{l}\text { LC-ESI-MS, FT-ICR- } \\
\text { MS }\end{array}$ & $\mathrm{N}$ & $\mathrm{N}$ & $\mathrm{N}$ & [16] \\
\hline Water & TBBPA degradation products & $\mathrm{N}$ & SPE & $\mathrm{N}$ & GC-MS, LC-MS & $\mathrm{N}$ & $\mathrm{N}$ & $\mathrm{N}$ & [17] \\
\hline $\begin{array}{l}\text { Tap water, river water, } \\
\text { waste water, urine, } \\
\text { and juice }\end{array}$ & $\begin{array}{l}\text { TBBPA BAE, TBBPA BDBPE, } \\
\text { TBBPS BGE, TBBPA BHEE }\end{array}$ & Filtration & SPME & $\mathrm{N}$ & HPLC-DAD & $45.5-126.2$ & $1.8-9.1$ & $130-630$ & [36] \\
\hline $\begin{array}{l}\text { River water and waste } \\
\text { water }\end{array}$ & $\begin{array}{l}\text { TBBPA BAE, TBBPA BDBPE, } \\
\text { TBBPS BDBPE, TBBPA BHEE }\end{array}$ & Filtration & SPME & $\mathrm{N}$ & HPLC-UV & $86.5-103.6$ & $3.6-6.8$ & $400-900$ & [37] \\
\hline $\begin{array}{l}\text { Tap water, river water, } \\
\text { and waste water }\end{array}$ & $\begin{array}{l}\text { TBBPA BAE, TBBPA BHEE, } \\
\text { TBBPA BGE, TBBPS BAE }\end{array}$ & Filtration & LLE & $\mathrm{N}$ & EESI-MS/MS & $\mathrm{N}$ & $\mathrm{N}$ & $50-4600$ & [47] \\
\hline $\begin{array}{l}\text { Tap water, river water, } \\
\text { and waste water }\end{array}$ & $\begin{array}{l}\text { TBBPA BAE, TBBPA BHEE, } \\
\text { TBBPA BGE, TBBPS BAE, TBBPA } \\
\text { MAE, TBBPA MHEE, TBBPA } \\
\text { MGE, }\end{array}$ & Filtration & LLE & $\mathrm{N}$ & HPLC-EESI-MS/MS & $81.3-114.9$ & $\mathrm{~N}$ & $160-1960$ & [48] \\
\hline $\begin{array}{l}\text { Reaction mixture } \\
\text { (methanol/water, } \\
1 / 1 \text { ) }\end{array}$ & TBBPA oxidation products & $\begin{array}{l}\text { Quenched with } \\
\text { L-ascorbic acid }\end{array}$ & LLE & $\mathrm{N}$ & GC-MS & $\mathrm{N}$ & $\mathrm{N}$ & $\mathrm{N}$ & [55] \\
\hline $\begin{array}{l}\text { Water reaction } \\
\text { solution }\end{array}$ & TBBPA oxidation products & $\begin{array}{l}\text { Quenched with } \\
\mathrm{NaHSO}_{3} \text { solution }\end{array}$ & $\mathrm{N}$ & $\mathrm{N}$ & GC-MS & $\mathrm{N}$ & $\mathrm{N}$ & $\mathrm{N}$ & [56] \\
\hline Water & TBBPA degradation products & $\mathrm{N}$ & LLE & $\mathrm{N}$ & $\begin{array}{l}\text { LC-LTQ-Orbitrap-ESI- } \\
\text { MS, LC-ESI-MS/MS }\end{array}$ & $\mathrm{N}$ & $\mathrm{N}$ & $\mathrm{N}$ & [57] \\
\hline Herring gull eggs & $\begin{array}{l}\text { TBBPA BAE, TBBPA BDBPE, } \\
\text { TBBPS BDBPE }\end{array}$ & $\begin{array}{l}\text { Ground with } \\
\text { diatomaceous earth }\end{array}$ & ASE & GPC, SPE-SiOH & HPLC-APPI-MS/MS & $55-89$ & $16-29$ & $0.03-1.28 \mathrm{ng} / \mathrm{g} \mathrm{ww}$ & [3] \\
\hline Soil and plant & TBBPA degradation products & Freeze dried & Shaking for extraction $(\mathrm{MeOH})$ & $\mathrm{N}$ & GC-MS & $\mathrm{N}$ & $\mathrm{N}$ & $\mathrm{N}$ & [8] \\
\hline Sediment & TBBPA BAE & Freeze dried & ASE & GPC, SPE-SiOH & HPLC-APCI-MS/MS & $\mathrm{N}$ & $\mathrm{N}$ & $\mathrm{N}$ & [12] \\
\hline Soil & TBBPA degradation products & Freeze dried & Shaking for extraction $(\mathrm{MeOH})$ & $\mathrm{N}$ & LC-MS & $\mathrm{N}$ & $\mathrm{N}$ & $\mathrm{N}$ & [18] \\
\hline $\begin{array}{l}\text { Sediment and sludge } \\
\text { samples }\end{array}$ & TBBPA BDBPE & $\begin{array}{l}\text { Drying }\left(40^{\circ} \mathrm{C} \text { and }\right. \\
\text { freeze dried })\end{array}$ & $\begin{array}{l}\text { Pressurized fluid extraction } \\
\text { (PFE) and fluidized bed } \\
\text { extraction }\end{array}$ & $\mathrm{N}$ & HPLC-DAD & $35-98$ & $\mathrm{~N}$ & $10-30$ & [19] \\
\hline Sludge & TBBPA degradation products & $\begin{array}{l}\text { Acidified with } \mathrm{HCl} \\
(1 \mathrm{M}) \text { to } \mathrm{pH} 2\end{array}$ & Extracted with ethyl acetate & $\mathrm{N}$ & LC-MS & $\mathrm{N}$ & $\mathrm{N}$ & $\mathrm{N}$ & [20] \\
\hline $\begin{array}{l}\text { Soil, sediment, and } \\
\text { sewage sludge }\end{array}$ & TriBBPA, DBBPA, MBBPA & Freeze dried & $\begin{array}{l}\text { Pressurized liquid extraction- } \\
\text { DCM/MeOH }(1 / 9, v / v)\end{array}$ & SPE-C18 cartridges & LC-ESI-MS/MS & $42-120$ & $6.1-8.3$ & $0.6-66$ & [28] \\
\hline $\begin{array}{l}\text { Sediment, sludge, and } \\
\text { biological tissue } \\
\text { samples }\end{array}$ & TriBBPA, DBBPA, MBBPA & $\begin{array}{l}\text { Centrifugation; } \\
\text { grounded with } \\
\text { anhydrous } \mathrm{Na}_{2} \mathrm{SO}_{4}\end{array}$ & Soxhlet extraction (MTBE) & SPE-C18 cartridges & LC-ESI-MS/MS & $72.3-96.6$ & $7.9-9.6$ & $\mathrm{~N}$ & [29] \\
\hline Standards & $\begin{array}{l}\text { TBBPA BME, TBBPA BAE, } \\
\text { TBBPA BHEE,TBBPA BDBPE }\end{array}$ & $\mathrm{N}$ & Silica; SPE-HLB & $\mathrm{N}$ & HPLC-UV & 23-99 & $\mathrm{N}$ & $\mathrm{N}$ & [30] \\
\hline $\begin{array}{l}\text { Soil, sediment, and } \\
\text { sewage sludge }\end{array}$ & TBBPA BDBPE & Freeze dried & $\begin{array}{l}\text { Soxhlet extraction (hexane/ } \\
\text { acetone, } 1: 1, \mathrm{v} / \mathrm{v} \text { ) }\end{array}$ & $\begin{array}{l}\text { Silica/alumina } \\
\text { column and GPC }\end{array}$ & GC-ECNI-MS & $87.6-105.5$ & $\mathrm{~N}$ & 1.5 & [46] \\
\hline Air & TBBPA BDBPE & & $\begin{array}{l}\text { Soxhlet extraction (hexane/ } \\
\text { acetone) }\end{array}$ & Silica gel column & $\begin{array}{l}\text { GC-EI-MS, GC-ECNI- } \\
\text { MS }\end{array}$ & 95 & 23 & $\mathrm{~N}$ & [44] \\
\hline Air & TBBPA BDBPE & Freeze dried & $\begin{array}{l}\text { Soxhlet extraction (hexane/ } \\
\text { acetone, } 1: 1, \mathrm{v} / \mathrm{v} \text { ) }\end{array}$ & $\begin{array}{l}\text { Silica/alumina } \\
\text { column and GPC }\end{array}$ & GC-ECNI-MS & $87.6-105.5$ & $\mathrm{~N}$ & 1.5 & [46] \\
\hline
\end{tabular}

N: Not applied.

N: Not applied.
a ng/mL applied for solid sample; $\mathrm{ng} / \mathrm{L}$ applied for water sample; $\mathrm{pg} / \mathrm{m}^{3}$ applied for air sample $\mathrm{N}$ : not applied. 
and biota samples [32]. However, severalcommercial cartridges showed poor recoveries because target analytes were strongly absorbed by the sorbents of the cartridges and could not be adequately eluted [10].

2.1.1.3. Solid-phase microextraction. As one of solventless extraction techniques, solid-phase microextraction (SPME) is also used in many applications $[33,34]$. Wang et al. reported an in situ synthesized capillary poly monolith as the SPME medium for simultaneous extraction of three BFRs, including TBBPA [35].

Some novel solid phases, including mesoporous cellular foams (MCFs), mesoporous silica materials, and phenyl-modified mesoporous materials, were synthesized and used as fiber coating materials for SPME [36]. By using a stainless steel wire as a supporting core, fibers were prepared with a sol-gel method and immobilized for extraction of TBBPA/S and TBBPA/S derivatives. The recoveries for this method were between $86.5 \%$ and $103.6 \%$ and the extraction efficiency was 3.5-fold higher than commercial fibers [37].

2.1.1.4. Dispersive liquid-liquid microextraction. The dispersive liquidliquid microextraction (DLLME) technique is a rapid preconcentration method with several advantages, including low cost, high recovery, and high enrichment factor [38]. By using this method, TBBPA and its five derivatives could be extracted using ultrasoundDLLME, which provided recoveries of about $80-100 \%$ for tap water, river water, or chemical wastewater, and $45-120 \%$ for urine or fruit juice samples [36].

2.1.1.5. Extraction with nanomaterials. Nanomaterials have attracted extensive interest in almost all the areas of analytical chemistry due to their unique chemical and physical properties. The application of nanomaterials also proves their merits in environmental analysis [39]. Carbon-doped $\mathrm{Fe}_{3} \mathrm{O}_{4}$ nanoparticles prepared using a facile hydrothermal reaction of glucose with iron resource were used as a magnetic solid-phase extraction (MSPE) sorbent to rapidly extract TBBPA from environmental waters with a recovery range of 95-107\% [40]. As a two-dimensional carbon nanostructure, graphene has been chosen as the sorbent in SPE and SPME because of its large surface area. Graphenized pencil lead fiber was prepared and used for the extraction of TBBPA from tap water and effluent samples with spike recoveries ranging from $68.5 \%$ to $105.1 \%$. As compared with commercially available fibers, the developed fiber showed excellent chemical stability, in addition to being low cost and having an extremely long life span [41].

\subsubsection{Soil, sediment, and biotic samples}

2.1.2.1. Accelerated solvent extraction. Sample pretreatment for TBBPA analysis in sewage sludge and soil has previously been discussed in several review papers $[2,42]$. For TBBPA derivatives, ASE and sonication extraction have been used, with $D C M /$ hexane $(1: 1 \mathrm{v} / \mathrm{v})$ as a solvent $[7,12]$. TBBPA BAE and TBBPA BDBPE were extracted from mollusks, soils, and sediments, and the recoveries were $73-85 \%$. In the case of herring gull eggs, the derivate recoveries ranged from $55 \%$ to $89 \%$ after ASE [3]. Good recoveries of some derivatives, including by-products, were also achieved for mollusks and earthworm pretreatment $[7,12]$.

2.1.2.2. Sonication-assisted extraction. Sonication extraction was applied for extraction of target substances from mollusks, using a solvent mixture containing $10 \mathrm{~mL}$ DCM/hexane (8/2, v/v) [10]. TBBPA derivatives can be extracted from the muscle tissue of either lean or fatty fish using acetonitrile extraction coupled with dispersive SPE and a combination of C18 and primary-secondary amine sorbents. Results showed that the recovery method for both matrices ranged from $80 \%$ to $115 \%$ [43].

\subsection{Cleanup}

To further eliminate impurities in the extracts and decrease the effects of matrices in the nonwater samples, GPC, silica gel column, and Florisil can be used. Commercially available SPE tubes have good applicability for the cleanup of residue extracted from soil, sediment, and biota samples [7,10].

\subsection{Air sample}

The air sampler equipped with XAD resin as the absorption material was usually used for collecting the air sample [13]. XAD resin extraction coupled with silica column purification process showed better recoveries for TBBPA BDBPE in air samples, ranged from $87.6 \%$ to $105.5 \%$ [44].

\section{Analytical technique}

To date, MS continues to be a distinctly powerful method to detect pollutants in the environment, especially at trace levels. The application of MS can be used to elucidate the structure of chemicals and characterize TBBPA derivatives while some chemicals cannot be efficiently ionized, and thus, cannot generate specific ion clusters for quantitative determination.

\subsection{Quantitative measurement of TBBPA/S or their derivatives}

\subsubsection{Mass spectrometry}

MS has been frequently used for TBBPA analysis. For instance, after derivatization in the sample preparation step, TBBPA can be analyzed using GC-MS [45]. However, LC-MS has been applied more frequently because there is no need of derivatization [2]. Regarding TBBPA/S derivatives, LC with diode array detection (LC-DAD) was initially used to analyze TBBPA BDBPE, but with a low sensitivity [19]. Afterwards, GC-MS was optimized and applied to the analysis of TBBPA BDBPE [46] but some results were conflicting $[3,7]$. This phenomenon seems to be the result of thermal degradation and the correspondent decomposition of derivatives in the temperature programming of GC-MS [14]. For air samples, GCMS has been used to determine TBBPA DBPE in the Great Lakes atmosphere and the concentration ranged from 0.19 to $1.3 \mathrm{pg} / \mathrm{m}^{3}$. Several methods based on LC-MS were developed and some of them showed good sensitivity. Atmospheric pressure photoionization (APPI) has proven to have the most efficient ionization for more nonpolar MTDs such as TBBPA BAE, TBBPA BDBPE, and TBBPS BDBPE, which have been found in bird eggs. The $[\mathrm{M}+\mathrm{O}]^{+}$cluster yielded under APPI ionization was selected for quantitative determination, with an instrument detection limit (IDL) range of $12-112 \mathrm{pg}$ [3] (Fig. 2A). Under atmospheric pressure chemical ionization (APCI)negative ionization mode, TBBPA BAE undergoes ether bond breakage. The cluster formed $\left[\mathrm{M}-\mathrm{C}_{2} \mathrm{H}_{5}\right]^{-}$can be used for quantitatively determining TBBPA derivatives (Fig. 2B). By using the ultrahigh pressure liquid chromatography (UHPLC)-Orbitrap Fusion mass spectrometer, Liu et al. identified TBBPA MHEE and TBBPA MGE in water, and the product clusters $[\mathrm{M}-\mathrm{H}]^{-}$, which can be used for quantitative determination. The IDLs for TBBPA MHEE and TBBPA MGE were found to be 0.5 and $0.6 \mathrm{pg}$, respectively (Fig. 2C). The concentration of the two chemicals is up to $88.5 \mathrm{ng} / \mathrm{L}$ in waste water [10].

To increase sensitivity, extractive electrospray ionization-MS (EESI-MS) was used, which proved to be capable of detecting chemicals in wastewater and undiluted urine, showing promising applications for the determination of pollutants in the environmental samples [26]. Under ambient conditions, active silver cations $\left(\mathrm{Ag}^{+}\right)$were generated by electrospraying a silver nitrate methanol solution that collide with neutral MTDs molecules to form $[\mathrm{M}+\mathrm{Ag}]^{+}$ complexes of the analytes sequentially. The instrumental limits of 
(A)

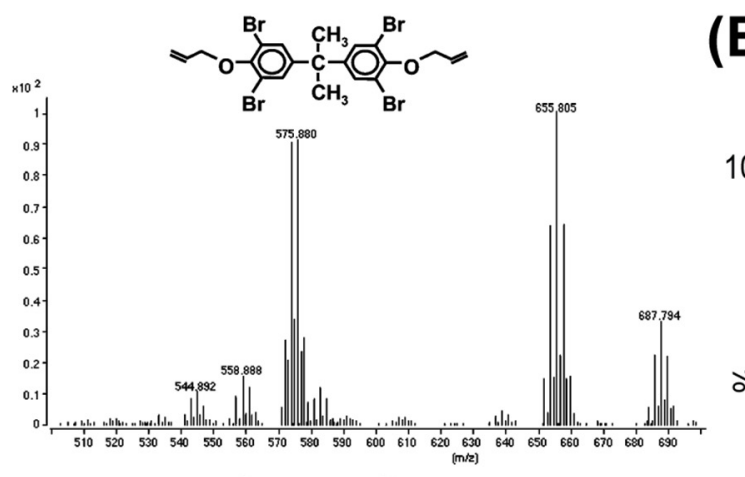<smiles>CC(C)(c1cc(Br)c(OCC(Br)CBr)c(Br)c1)c1cc(Br)c(OCC(Br)CBr)c(Br)c1</smiles>

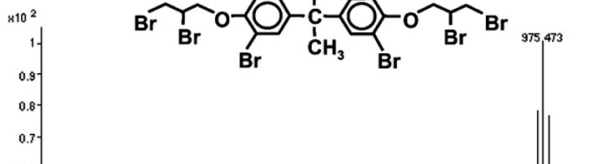<smiles>C=[IH]</smiles>

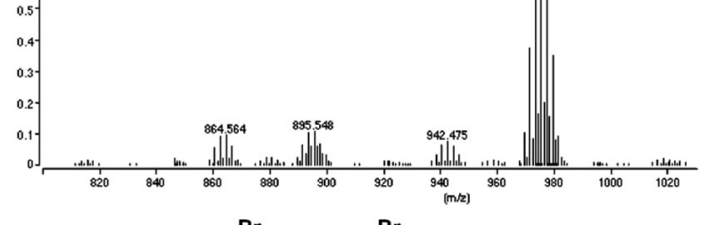<smiles>C#CC(=O)[C@H](C)C#CCOc1c(Br)cc(S(=O)(=O)c2cc(Br)c(OCC(Br)CBr)c(Br)c2)cc1Br</smiles>

(C)
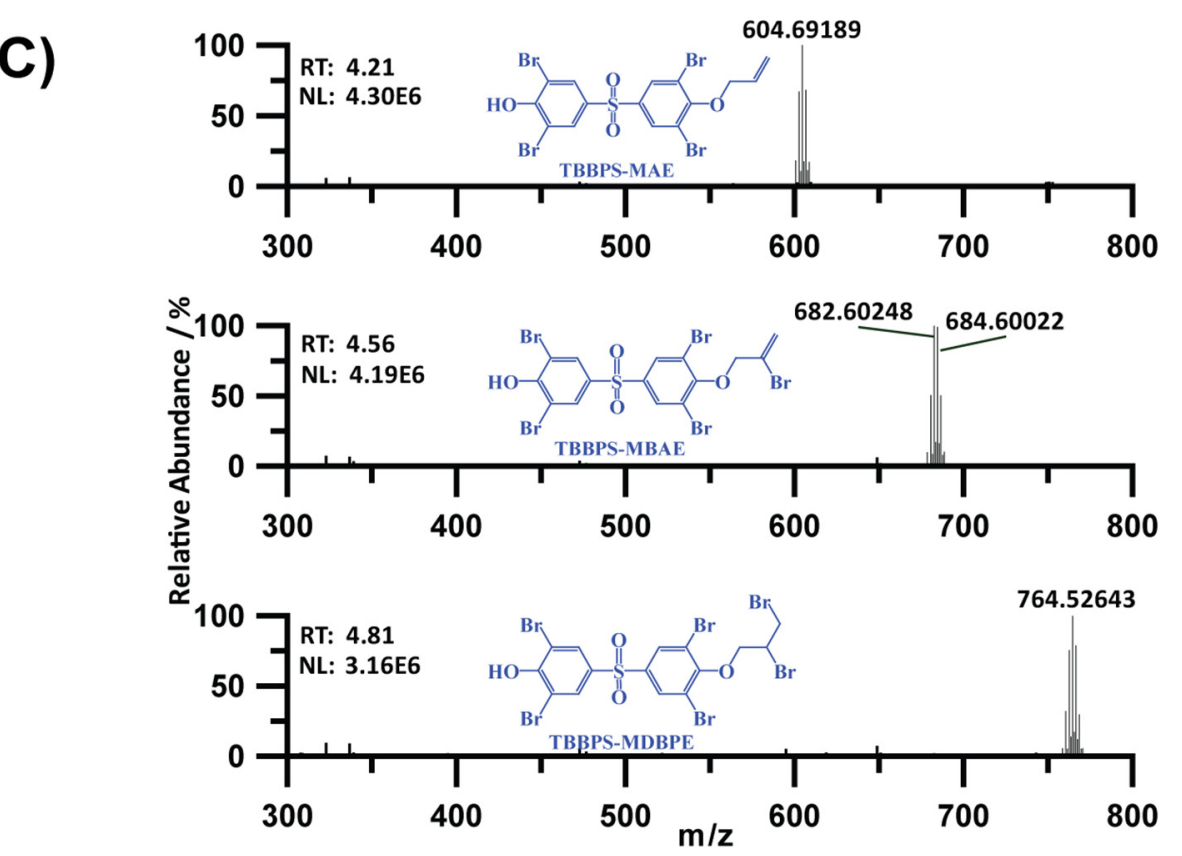

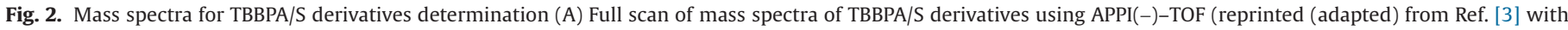

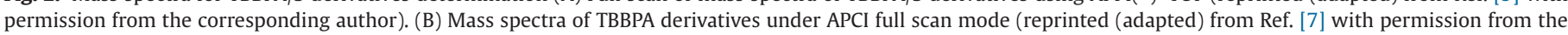
American Chemical Society). (C) HRMS spectra of TBBPS derivatives using Orbitrap Fusion TMS (reprinted (adapted) from Ref. [11]). 
(A)

(B)
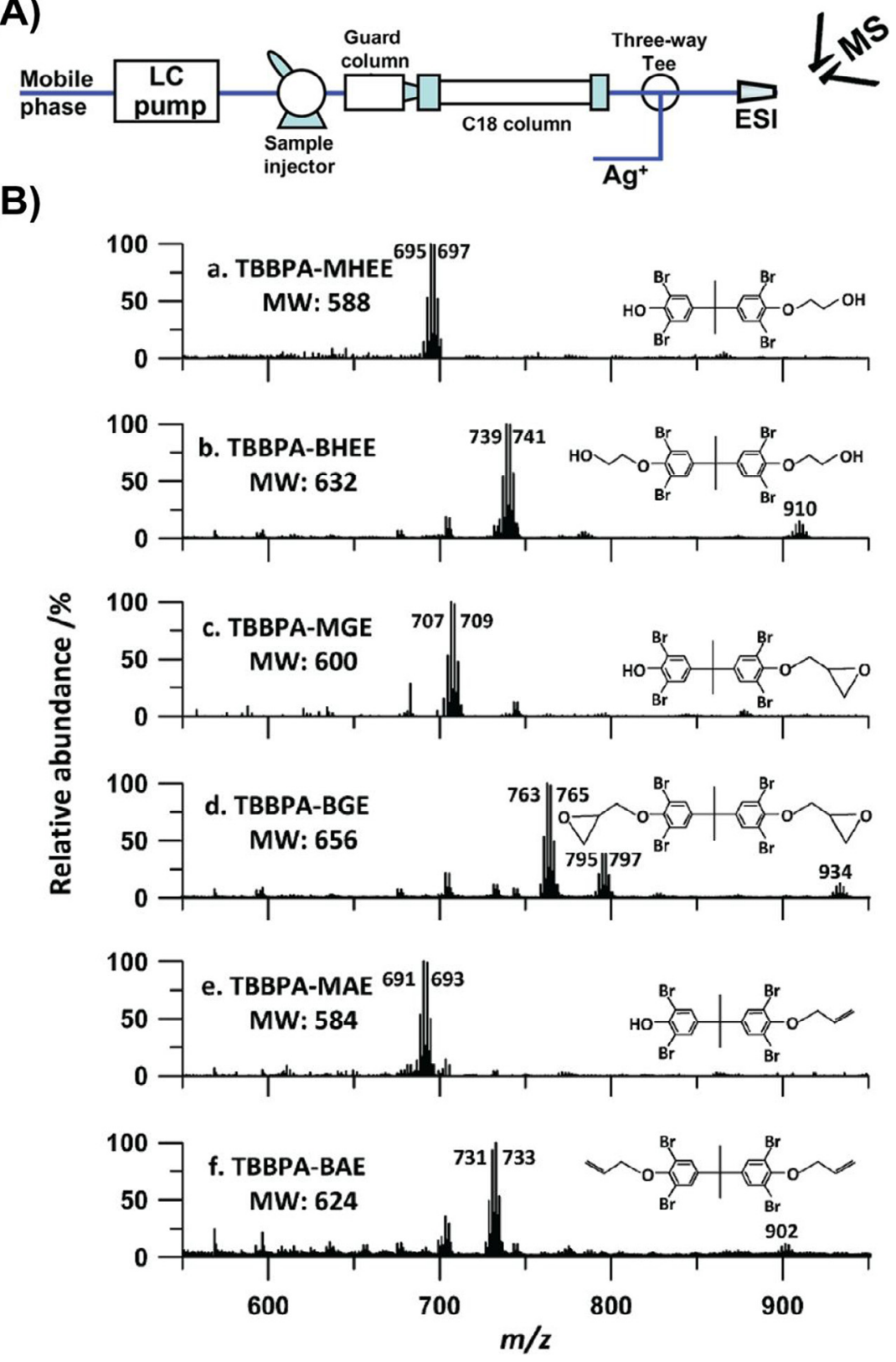

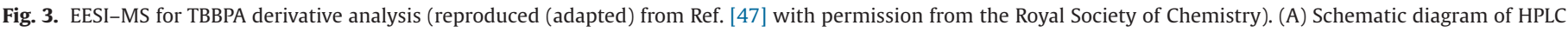
$\mathrm{Ag}^{+}$postcolumn derivatization MS/MS system. (B) The ESI-MS spectra of $\mathrm{Ag}^{+}-\mathrm{TBBPA}$ derivatives $\left([\mathrm{M}+\mathrm{Ag}]^{+}\right)$.

detections (LODs) of TBBPA bis(2-hydroxyethyl ether) (TBBPA BHEE), TBBPA bis(glycidyl ether) (TBBPA BGE), TBBPA BAE, and TBBPS bis(allyl ether) (TBBPS BAE) were $0.37,0.050,0.76$, and $4.6 \mathrm{ng} / \mathrm{mL}$, respectively [47]. The concentration of the four compounds ranged from not detected (ND) to $19,900 \mathrm{ng} / \mathrm{mL}$ in industrial water and ND to $300 \mathrm{ng} / \mathrm{mL}$ in river water. However, in tap water, only TBBPA BGE could be detected at $30 \mathrm{ng} / \mathrm{mL}$. As $\mathrm{Ag}^{+}$has been found to react with the main TBBPA derivatives, some derivatives were found to form complexes of $[\mathrm{M}+\mathrm{Ag}] \mathrm{NO}_{3}$ rapidly in the liquid phase, and these complexes could be effectively electrosprayed to generate $[\mathrm{M}+\mathrm{Ag}]^{+}$for sensitive mass analysis. Therefore, this mechanism provided $\mathrm{Ag}^{+}$for postcolumn derivatization of MTDs, enabling sensitive ESI. Coupled with high-performance LC (HPLC) for analyte separation and $\mathrm{Ag}^{+}$ addition, chemicals were sensitively detected by ESI-MS (Fig. 3). These methods offered an alternative analytical choice for detection of TBBPA derivatives, especially, as they cannot be ionized through commercially available ionization sources $[47,48]$. However, the introduction of large concentrations of $\mathrm{AgNO}_{3}$ could increase the possibility of instrument damnification. Until today, the EESIMS method has only been applied in the simple environmental matrix analysis and attempts at analyzing TBBPA/S BDBPE with it have failed. By using HPLC-MS for analysis of TBBPA derivatives, the phenolic hydroxyl group could be considered an important factor for sensitivity. The hydrogen of the phenolic hydroxyl is easily ionized under negative ionization mode, which highly improved the detection sensitivity of mono-modified TBBPA derivatives by HPLC-MS; this could explain the low IDL of mono-modified TBBPA derivatives.

\subsubsection{Immunoassay}

Although the instrumental analysis based on MS provides data with high sensitivity or specificity, the expensive instruments 
required cannot be used for rapid or portable analysis. In addition, analysis of MTDs using MS continues to be a concern due to thermal degradation and ionization problems. Some studies have been undertaken to develop analysis approaches for the detection of TBBPA other than MS. An enzyme-linked immunosorbent assay (ELISA) was developed based on antibodies to detect traces of TBBPA in the environment using this method's high specificity, sensitivity, and throughput for determination of TBBPA in water, soils, and sediments. The limit of detection (LOD) and the inhibition half-maximal concentration of TBBPA were found to be $0.05 \mathrm{ng} / \mathrm{mL}$. Crossreactivity values of the ELISA with TBBPA derivatives were $<0.05 \%$ [23]. Alpacas were also immunized with a TBBPA hapten coupled to thyroglobulin, which was applied to quantitatively determine the concentration of TBBPA at trace levels $(\sim 10 \mathrm{ng} / \mathrm{g})$ in the environment [49]. A selective biotin-streptavidin-amplified ELISA for the measurement of TBBPA within an LOD $\left(\mathrm{IC}_{10}\right)$ has been developed [50].

\subsubsection{Detection with nanomaterials and technology}

Nanomaterials have been used not only for pollutant extraction, as mentioned above, but also for detection [39]. To detect TBBPA in the environmental samples, graphene-modified carbon electrodes have been developed using electrochemical sensors electrochemically. The large surface area of graphene, together with enhanced electrocatalytic activity of graphene surface, provided high sensitivity with an LOD at $125 \mathrm{ng} / \mathrm{L}$ in the rainwater and lake water samples [24]. Zhao et al. used electrochemiluminescence based on a gold nanomaterial-modified electrode to successfully determine TBBPA in fish samples with an LOD as low as $2 \mathrm{ng} / \mathrm{L}$ [51].

SERS has distinct properties for the detection of environmental contaminants. By using SERS spectroscopy, magnetic gold nanoclusters were modified as receptor material to detect TBBPA [25]. The modulation of TBBPA on nanomaterials absorbed by Raman spectroscopy provides a high sensitivity for measurement with the LOD $5.0 \mathrm{pg} / \mathrm{mL}$ in water [25]. Quantum dots (QDs) have been widely developed and used as chemical or biological probes for detecting or tracking tools due to their excellent optical properties when compared with traditional fluorescent dyes [52]. The surfaces of QDs can be modified as the receptors of target chemicals. Based on this mechanism, high-affinity imprinted polymers have been capped onto the surface of QDs for use as sensors for the selective determination of traces of TBBPA in the water and soil samples and the LOD reached to $8160 \mathrm{ng} / \mathrm{mL}$ [53].

\subsection{Transformation product characterization}

To unravel the fates of TBBPA and its derivatives, the identification of unknown products is frequently performed using LC/GC coupled with MS [54,55].

\subsubsection{MS for molecular structure elucidation}

It is difficult to describe the complicated degradation pathways of TBBPA due to their exposure to a wide spectrum of environmental matrices (Fig. 4A). For instance, solar light could induce the photolysis of TBBPA as the result of magnetic isotope effect hydrolysis, singlet oxygen oxidation, and reductive debromination [16]. Under these conditions, hydroxyl tribromoBPA (HtriBBPA) emerges as a direct photolysis product of TBBPA and various products are formed sequentially [18]. $\mathrm{H}_{2} \mathrm{O}$ was applied as an exposure matrix under simulated solar light irradiation. The isotopic proportion of the peak or fragment ion was monitored based on MS and metabolites, including tribromo-BPA, dibromo-BPA, and monobromo-BPA, were identified [16]. By using a GC-ion trap mass spectrometer, Bastos et al. used $\mathrm{KMnO}_{4}$ as an oxidative agent to investigate the rates of TBBPA degradation in water systems (Fig. 4A) [56]. Pang et al. developed negative ESI-triple quadrupole-MS (ESI-
QqQ-MS) for fast detection of brominated oxidation products, and several degradation products have been identified using this method (Fig. 4A) [15]. With high resolution, time-of-flight MS (TOF-MS) was also used for the analysis of biotransformation of TBBPA incubated with freshwater microalgae (Fig. 4A) [9].

Radioactive isotope labeling has been used for the identification of products using MS. By using ${ }^{14} \mathrm{C}$-labeled TBBPAs $\left({ }^{14} \mathrm{C}\right.$ TBBPAs) as starting chemicals, transformation properties can be characterized based on MS. The transformation of ${ }^{14} \mathrm{C}$-TBBPA in the soil and in the soil-plant system was investigated using GC-MS (Fig. 4A) [8,18]. Another complex exposure system was established that could be used to investigate the impact of interconnected aerobic and anaerobic transformations on TBBPA. GC-MS and LCMS have been used to identify the degradation products of TBBPA produced by oxidation and photolysis. Biological-transformationdependent degradation of TBBPA was characterized by comparing the sludge with or without sterilization and by monitoring the radioactivity extracted (Fig. 4A) [20].

As high-resolution MS (HRMS), UHPLC-Orbitrap MS has proven to be a high-resolution tool for quantitatively determining novel contaminants in the environment, providing greater confidence in identifying unknown chemicals [5]. The detection resolution is improving with the development of HRMS. Under the full-scan mode, Orbitrap HRMS provides resolutions of 450,000 full width at half maximum (FWHM) at $m / z 200$, which is much higher than conventional TOF-MS. Orbitrap HRMS has been used for the identification and quantitation of novel TBBPA/S derivatives (Fig. 2C) [10,11]. The accurate $m / z$ values ( $<5 \mathrm{ppm}$ ), detailed isotopic distribution, and comparable quantitation sensitivity of ESI-MS/MS were all achieved in the full scan process of Orbitrap HRMS. In addition, the retrospective analysis helped identify three novel brominated contaminants in mollusk samples. Based on this approach, the detectable concentrations (dry weight) of TBBPS MAE, TBBPS MBAE, and TBBPS MDBPE were in the range of $28-394 \mu \mathrm{g} / \mathrm{g}$ in technical TBBPS BDBPE and 0.1$4.1 \mathrm{ng} / \mathrm{g}$ in mollusks collected from the Bohai Sea in China [11]. The transformation of TBBPA catalyzed by naturally occurring laccase enzyme was investigated using GC with ion-trap tandem mass spectrometer (GC-ITMS/MS) and LC-MS [17]. The transformation of TBBPA in Xenopus laevis and mammal systems has been investigated [57].

\subsubsection{Preparation of $L C$}

Preparative LC was used to purify and enrich the potential products that provide enough samples to characterize the proposed structures of unknown chemicals. Radioactive isotope labeling was used to guide the collection of potential transformation products. For instance, using HPLC coupled to a diode array detector and an online radio flow detector, ${ }^{14} \mathrm{C}$-TBBPA and its transformation products were separated into peaks and collected for further identification after exposure to nitrifying activated sludge (NAS) [18]. Biological effect-guided chemical analyses, such as effect-directed analysis (EDA), have been frequently applied for identifying the main pollutants in the environmental samples responsible for the measured biological effect [58]. An EDA method with neural toxicity assay has been established. Collected unknown metabolites were identified as TBBPA BAE toxicants using preparative LC with APCI-Q-TOF-MS.

\subsection{Computational-aided transformation prediction}

In silico calculation is a quick, cost-effective approach to assess and predict chemical degradation potential, metabolites, and pathways at the screening level. Molecular descriptors have been applied and linked to biodegradation potential. For instance, HyperChem has been used to determine the charge and spin densities of the TBBPA radical for the elucidation of TBBPA pathways [17].

The University of Minnesota Pathway Prediction System (UM-PPS) has been frequently used to predict degradation or 
(A)

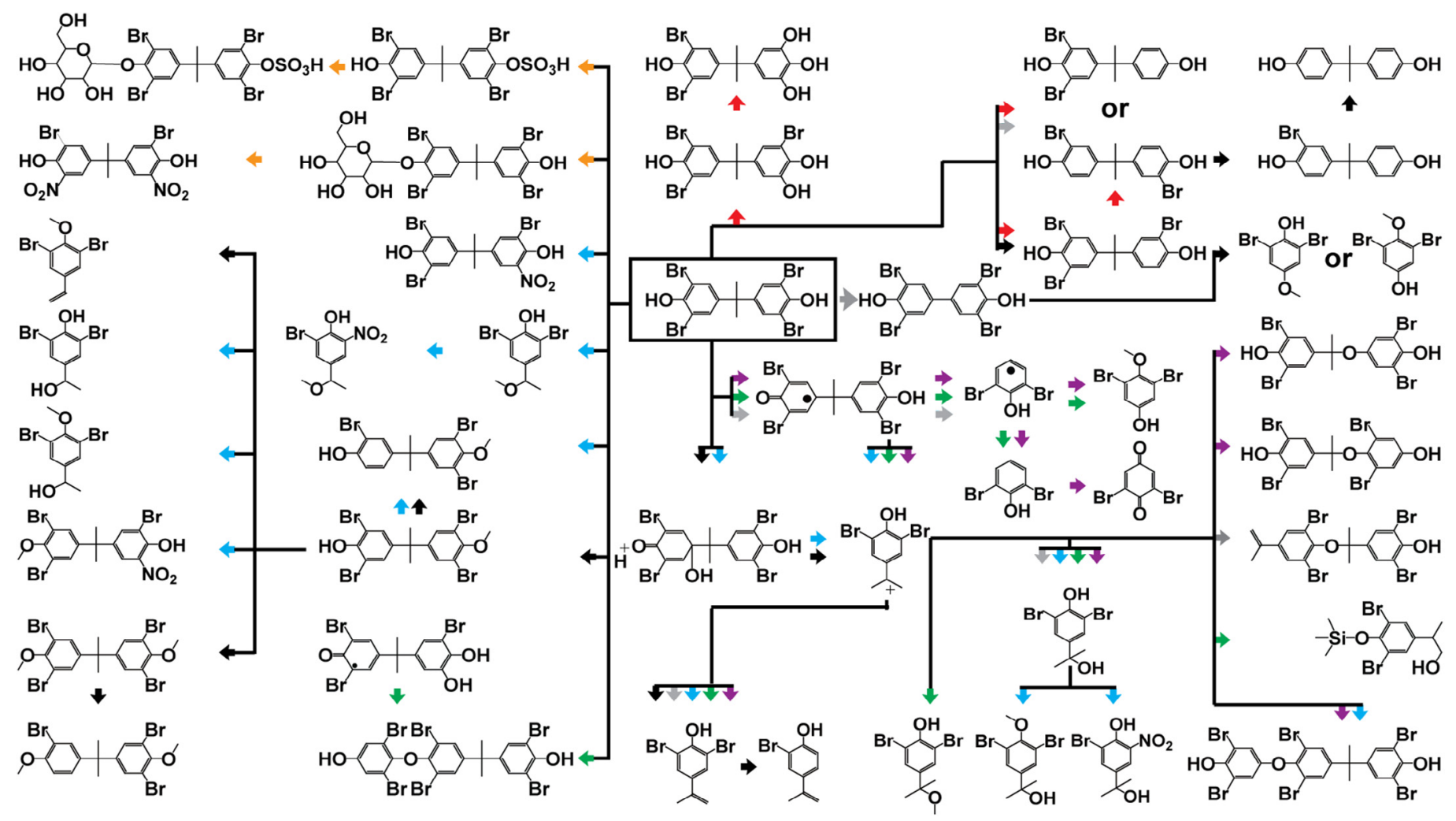

(B)

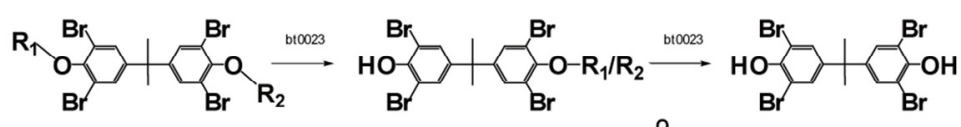

$\mathrm{R}_{1}=\mathrm{R}_{2}=-\mathrm{CH}_{2} \mathrm{CHBrCH}{ }_{2} \mathrm{Br}$ (TBBPA-BDBPE); $-\mathrm{CH}_{2} \mathrm{CH}=\mathrm{CH}_{2}$ (TBBPA-BAE); - $\mathrm{CH}_{2}-\mathrm{CHCH}_{2}$ (TBBPA-BGE); $-\mathrm{CH}_{2} \mathrm{CH}_{2} \mathrm{OH}$

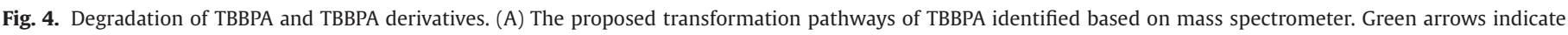

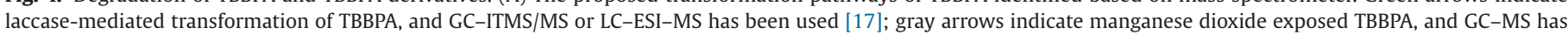

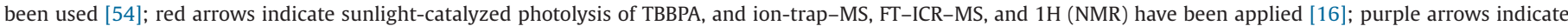

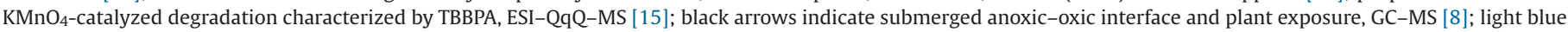

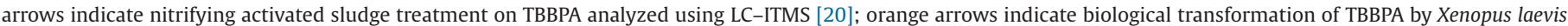
and mammals based on LC-QqQ-MS and TOF-MS [56]. (B) Degradation of TBBPA derivatives predicted by UM-PPS.

transformation of chemicals in the environment. By using this approach, microbially induced transformation of derivatives could be predicted using computational-aided transformation. When this technique has been combined with Q-TOF-MS, the presence of TBBPA MAE and TBBPA MDBPE has been successfully identified [7]. PPI was also used for screening the degradation or transformation of these serials of TBBPA/S derivatives (Fig. 4). Battery software can be applied in spectral identification [59].

\section{Perspectives}

At present, our understanding of the distribution, transportation, and transformation of TBBPA/S and MTDs in the environmental compartments is limited, in part because the pretreatment methods are not appropriate for simultaneous determination of MTDs [10,11]. Therefore, analysis of target MTDs in complex samples is still challenging and may not be capable of determining all the derivatives in the environmental samples. The analysis method based on HRMS is still an open field for quantitatively determining these chemicals. As an alternative method for MS, immune analysis has been applied for detecting TBBPA and has shown promising potential for detecting MTDs. The determination of target MTDs based on immunoanalysis with high sensitivity and specificity, such as time- resolved fluoroimmunoassay (TRFIA), may become a promising strategy [60,61]. Another the technique of MTD determination is the establishment of a MIP method combining nanotechnology or electrochemical technology.

The studies on TBBPA transformation have been mainly limited to laboratory exposure and these findings should be further investigated and confirmed in real environmental samples. However, there has been almost no documented investigation of TBBPS and TBBPA/S derivatives. In terms of understanding the transformation of TBBPA/S and their derivatives, the challenge of seeking unknown transformation products of TBBPA/S derivatives at lowlevel concentrations remains. In previous years, GC-MS could be used by matching the observed mass fragments with a mass spectra database. However, this method is highly dependent on derivatization with the phenolic hydroxyl group as the reactive group. This approach may result in excluding some products, because not all products can be derivatized. Thus, as alternatives, HRMS methods, including fourier transform ion cyclotron resonance (FT-ICR)-MS, Orbitrap, and nuclear magnetic resonance (NMR), are increasingly being applied to seek novel transformation products in the environmental compartments. The application of calculation software could narrow the number of unknown candidates according to the consensus method. Strategies combining radioactive labeling, mass 
spectrometry characterization, and battery software applications should become the new trends for the identification of unknown metabolites or TBBPA/S and their derivatives in environmental matrices [59].

\section{Acknowledgments}

The authors acknowledge financial support from the National Natural Science Foundation of China (Grant Nos. 21377155, 21377159, 21425731, and 21321004) and the Strategic Priority Research Program of the Chinese Academy of Sciences (Grant No. XDB14010400).

\section{References}

[1] C.A. de Wit, An overview of brominated flame retardants in the environment, Chemosphere 46 (2002) 583-624.

[2] A. Covaci, S. Voorspoels, M.A.E. Abdallah, T. Geens, S. Harrad, R.J. Law, Analytical and environmental aspects of the flame retardant tetrabromobisphenol-A and its derivatives, J. Chromatogr. A 1216 (2009) 346-363.

[3] R.J. Letcher, S. Chu, High-sensitivity method for determination of tetrabromobisphenol-S and tetrabromobisphenol-A derivative flame retardants in great lakes herring gull eggs by liquid chromatography-atmospheric pressure photoionization-tandem mass spectrometry, Environ. Sci. Technol. 44 (2010) 8615-8621.

[4] T. Reistad, E. Mariussen, A. Ring, F. Fonnum, In vitro toxicity of tetrabromobisphenol-A on cerebellar granule cells: cell death, free radical formation, calcium influx and extracellular glutamate, Toxicol. Sci. 96 (2007) 268-278.

[5] S.D. Richardson, T.A. Ternes, Water analysis: emerging contaminants and current issues, Anal. Chem. 86 (2014) 2813-2848.

[6] G. Eichenbaum, M. Johnson, D. Kirkland, P. O'Neill, S. Stellar, J. Bielawne, et al., Assessment of the genotoxic and carcinogenic risks of p-nitrophenol when it is present as an impurity in a drug product, Regul. Toxicol. Pharmacol. 55 (2009) 33-42.

[7] G.B. Qu, A.F. Liu, T. Wang, C.L. Zhang, J.J. Fu, M. Yu, et al., Identification of tetrabromobisphenol A allyl ether and tetrabromobisphenol A 2,3dibromopropyl ether in the ambient environment near a manufacturing site and in mollusks at a coastal region, Environ. Sci. Technol. 47 (2013) 4760-4767.

[8] F.F. Sun, B.A. Kolvenbach, P. Nastold, B.Q. Jiang, R. Ji, P.F.X. Corvini, Degradation and metabolism of tetrabromobisphenol A (TBBPA) in submerged soil and soil-plant systems, Environ. Sci. Technol. 48 (2014) 14291-14299.

[9] F.Q. Peng, G.G. Ying, B. Yang, Y.S. Liu, H.J. Lai, G.J. Zhou, et al., Biotransformation of the Flame Retardant Tetrabromobisphenol-a (Tbbpa) by Freshwater Microalgae, Environ. Toxicol. Chem. 33 (2014) 1705-1711.

[10] A.F. Liu, G.B. Qu, C.L. Zhang, Y. Gao, J.B. Shi, Y.G. Du, et al., Identification of two novel brominated contaminants in water samples by ultra-high performance liquid chromatography-Orbitrap Fusion Tribrid mass spectrometer, J. Chromatogr. A 1377 (2015) 92-99.

[11] A.F. Liu, Y. Tian, N.Y. Yin, M. Yu, G.B. Qu, J.B. Shi, et al., Characterization of three tetrabromobisphenol-S derivatives in mollusks from Chinese Bohai Sea: a strategy for novel brominated contaminants identification, Sci. Rep. 5 (2015).

[12] G.B. Qu, J.B. Shi, T. Wang, J.J. Fu, Z.N. Li, P. Wang, et al., Identification of tetrabromobisphenol A diallyl ether as an emerging neurotoxicant in environmental samples by bioassay-directed fractionation and HPLC-APCI-MS/ MS, Environ. Sci. Technol. 45 (2011) 5009-5016.

[13] A. Covaci, S. Harrad, M.A. Abdallah, N. Ali, R.J. Law, D. Herzke, et al., Novel brominated flame retardants: a review of their analysis, environmental fate and behaviour, Environ. Int. 37 (2011) 532-556.

[14] J. Eriksson, S. Rahm, N. Green, A. Bergman, E. Jakobsson, Photochemical transformations of tetrabromobisphenol $\mathrm{A}$ and related phenols in water, Chemosphere 54 (2004) 117-126.

[15] S.Y. Pang, J. Jiang, Y. Gao, Y. Zhou, X. Huangfu, Y. Liu, et al., Oxidation of flame retardant tetrabromobisphenol a by aqueous permanganate: reaction kinetics, brominated products, and pathways, Environ. Sci. Technol. 48 (2014) 615-623.

[16] X.W. Wang, X.F. Hu, H. Zhang, F. Chang, Y.M. Luo, Photolysis kinetics, mechanisms, and pathways of tetrabromobisphenol A in water under simulated solar light irradiation, Environ. Sci. Technol. 49 (2015) 6683-6690.

[17] Y.P. Feng, L.M. Colosi, S.X. Gao, Q.G. Huang, L. Mao, Transformation and removal of tetrabromobisphenol A from water in the presence of natural organic matter via laccase-catalyzed reactions: reaction rates, products, and pathways, Environ. Sci. Technol. 47 (2013) 1001-1008.

[18] J. Liu, Y.F. Wang, B.Q. Jiang, L.H. Wang, J.Q. Chen, H.Y. Guo, et al., Degradation, metabolism, and bound-residue formation and release of tetrabromobisphenol $\mathrm{A}$ in soil during sequential anoxic-oxic incubation, Environ. Sci. Technol. 47 (2013) 8348-8354.

[19] R. Koppen, R. Becker, C. Jung, C. Piechotta, I. Nehls, Investigation of extraction procedures and HPLC-DAD/MS for the determination of the brominated flame retardant tetrabromobisphenol A bis(2,3-dibromopropylether) in environmental samples, Anal. Bioanal. Chem. 384 (2006) 1485-1492.
[20] F.J. Li, B.Q. Jiang, P. Nastold, B.A. Kolvenbach, J.Q. Chen, L.H. Wang, et al., Enhanced transformation of tetrabromobisphenol A by nitrifiers in nitrifying activated sludge, Environ. Sci. Technol. 49 (2015) 4283-4292.

[21] M. Ma, D. Crump, R. Farmahin, S.W. Kennedy, Comparing the effects of tetrabromobisphenol-A, bisphenol $\mathrm{A}$, and their potential replacement alternatives, Tbbpa-bis(2,3-dibromopropyl ether) and bisphenol S, on cell viability and messenger ribonucleic acid expression in chicken embryonic hepatocytes, Environ. Toxicol. Chem. 34 (2015) 391-401.

[22] R. Cruz, S.C. Cunha, S. Casal, Brominated flame retardants and seafood safety: a review, Environ. Int. 77 (2015) 116-131.

[23] T. Xu, J. Wang, S.Z. Liu, C. Lu, W.L. Shelver, Q.X. Li, et al., A highly sensitive and selective immunoassay for the detection of tetrabromobisphenol A in soil and sediment, Anal. Chim. Acta 751 (2012) 119-127.

[24] H.J. Chen, Z.H. Zhang, R. Cai, X.Q. Kong, X. Chen, Y.N. Liu, et al., Molecularly imprinted electrochemical sensor based on a reduced graphene modified carbon electrode for tetrabromobisphenol A detection, Analyst 138 (2013) 2769-2776.

[25] N.R. Kadasala, A. Wei, Trace detection of tetrabromobisphenol A by SERS with DMAP-modified magnetic gold nanoclusters, Nanoscale 7 (2015) 10931-10935.

[26] T. Einsle, H. Paschke, K. Bruns, S. Schrader, P. Popp, M. Moeder, Membraneassisted liquid-liquid extraction coupled with gas chromatography-mass spectrometry for determination of selected polycyclic musk compounds and drugs in water samples, J. Chromatogr. A 1124 (2006) 196-204.

[27] A. Bacaloni, L. Callipo, E. Corradini, P. Giansanti, R. Gubbiotti, R. Samperi, et al., Liquid chromatography-negative ion atmospheric pressure photoionization tandem mass spectrometry for the determination of brominated flame retardants in environmental water and industrial effluents, J. Chromatogr. A 1216 (2009) 6400-6409

[28] P. Guerra, E. Eljarrat, D. Barcelo, Simultaneous determination of hexabromocyclododecane, tetrabromobisphenol A, and related compounds in sewage sludge and sediment samples from Ebro River basin (Spain), Anal. Bioanal. Chem. 397 (2010) 2817-2824.

[29] S.G. Chu, G.D. Haffner, R.J. Letcher, Simultaneous determination of tetrabromobisphenol A, tetrachlorobisphenol A, bisphenol A and other halogenated analogues in sediment and sludge by high performance liquid chromatography-electrospray tandem mass spectrometry, J. Chromatogr. A 1097 (2005) 25-32.

[30] S. Jonsson, M. Horsing, Investigation of sorption phenomena by solid phase extraction and liquid chromatography for the determination of some ether derivatives of tetrabromobisphenol A, J. Phys. Org. Chem. 22 (2009) 1120-1126.

[31] Scientific opinion on tetrabromobisphenol A (TBBPA) and its derivatives in food, EFSA J. 9 (2011).

[32] Y.N. Li, Q.X. Zhou, Y.Y. Wang, X.J. Xie, Fate of tetrabromobisphenol A and hexabromocyclododecane brominated flame retardants in soil and uptake by plants, Chemosphere 82 (2011) 204-209.

[33] J.Q. Xu, J. Zheng, J.Y. Tian, F. Zhu, F. Zeng, C.Y. Su, et al., New materials in solid-phase microextraction, Trends Analyt. Chem. 47 (2013) 68-83.

[34] G. Ouyang, J. Pawliszyn, Recent developments in SPME for on-site analysis and monitoring, Trends Analyt. Chem. 25 (2006) 692-703.

[35] T.T. Yang, L.F. Zhou, J.Q. Qiao, H.Z. Lian, X. Ge, H.Y. Chen, Preparation of poly(trimethyl-2-methacroyloxyethylammonium chloride-co-ethylene glycol dimethacrylate) monolith and its application in solid phase microextraction of brominated flame retardants, J. Chromatogr. A 1291 (2013) 1-9.

[36] X.M. Wang, J.Y. Liu, Q. Liu, X.Z. Du, G.B. Jiang, Rapid determination of tetrabromobisphenol $\mathrm{A}$ and its main derivatives in aqueous samples by ultrasound-dispersive liquid-liquid microextraction combined with highperformance liquid chromatography, Talanta 116 (2013) 906-911.

[37] X.M. Wang, J.Y. Liu, A.F. Liu, Q. Liu, X.Z. Du, G.B. Jiang, Preparation and evaluation of mesoporous cellular foams coating of solid-phase microextraction fibers by determination of tetrabromobisphenol A, tetrabromobisphenol S and related compounds, Anal. Chim. Acta 753 (2012) 1-7.

[38] M. Rezaee, Y. Yamini, M. Faraji, Evolution of dispersive liquid-liquid microextraction method, J. Chromatogr. A 1217 (2010) 2342-2357.

[39] Q. Liu, Q.F. Zhou, G.B. Jiang, Nanomaterials for analysis and monitoring of emerging chemical pollutants, Trends Analyt. Chem. 58 (2014) 10-22.

[40] J. Yang, J.Y. Li, J.Q. Qiao, S.H. Cui, H.Z. Lian, H.Y. Chen, Magnetic solid phase extraction of brominated flame retardants and pentachlorophenol from environmental waters with carbon doped Fe304 nanoparticles, Appl. Surf. Sci. 321 (2014) 126-135.

[41] Q. Liu, M.T. Cheng, Y.M. Long, M. Yu, T. Wang, G.B. Jiang, Graphenized pencil lead fiber: facile preparation and application in solid-phase microextraction, J. Chromatogr. A 1325 (2014) 1-7.

[42] E. Eljarrat, D. Barcelo, Sample handling and analysis of brominated flame retardants in soil and sludge samples, Trends Analyt. Chem. 23 (2004) $727-736$.

[43] D. Lankova, O. Lacina, J. Pulkrabova, J. Hajslova, The determination of perfluoroalkyl substances, brominated flame retardants and their metabolites in human breast milk and infant formula, Talanta 117 (2013) 318-325.

[44] L.Y. Liu, M. Venier, A. Salamova, R.A. Hites, A novel flame retardant in the great lakes atmosphere: 3,3',5,5'-tetrabromobisphenol A bis(2,3-dibromopropyl) ether, Environ. Sci. Technol. Lett. 3 (2016) 194-199.

[45] Z.Y. Xie, R. Ebinghaus, R. Lohmann, O. Heemken, A. Caba, W. Puttmann, Trace determination of the flame retardant tetrabromobisphenol $A$ in the atmosphere by gas chromatography-mass spectrometry, Anal. Chim. Acta 584 (2007) 333-342.

[46] T. Shi, S.J. Chen, X.J. Luo, X.L. Zhang, C.M. Tang, Y. Luo, et al., Occurrence of brominated flame retardants other than polybrominated diphenyl ethers in 
environmental and biota samples from southern China, Chemosphere 74 (2009) 910-916.

[47] Y. Tian, J. Chen, Y.Z. Ouyang, G.B. Qu, A.F. Liu, X.M. Wang, et al., Reactive extractive electrospray ionization tandem mass spectrometry for sensitive detection of tetrabromobisphenol A derivatives, Anal. Chim. Acta 814 (2014) 49-54.

[48] Y. Tian, A.F. Liu, G.B. Qu, C.X. Liu, J. Chen, E. Handberg, et al., Silver ion postcolumn derivatization electrospray ionization mass spectrometry for determination of tetrabromobisphenol A derivatives in water samples, RSC Adv. 5 (2015) 17474-17481.

[49] J. Wang, C.R. Bever, Z. Majkova, J.E. Dechant, J. Yang, S.J. Gee, et al., Heterologous antigen selection of camelid heavy chain single domain antibodies against tetrabromobisphenol A, Anal. Chem. 86 (2014) 8296-8302.

[50] D. Bu, H.S. Zhuang, X.C. Zhou, G.X. Yang, Biotin-streptavidin enzyme-linked immunosorbent assay for detecting tetrabromobisphenol A in electronic waste, Talanta 120 (2014) 40-46.

[51] Z.H. Zhang, R. Cai, F. Long, J. Wang, Development and application of tetrabromobisphenol A imprinted electrochemical sensor based on graphene/ carbon nanotubes three-dimensional nanocomposites modified carbon electrode, Talanta 134 (2015) 435-442.

[52] M.J. Ruedas-Rama, E.A.H. Hall, Analytical nanosphere sensors using quantum dot-enzyme conjugates for urea and creatinine, Anal. Chem. 82 (2010) 90439049.

[53] Y.P. Chen, D.N. Wang, Y.M. Yin, L.Y. Wang, X.F. Wang, M.X. Xie, Quantum dots capped with dummy molecularly imprinted film as luminescent sensor for the determination of tetrabromobisphenol A in water and soils, J. Agric. Food Chem. 60 (2012) 10472-10479.
[54] S.D. Richardson, Environmental mass spectrometry: emerging contaminants and current issues, Anal. Chem. 84 (2012) 747-778.

[55] K.D. Lin, W.P. Liu, J. Gan, Reaction of tetrabromobisphenol A (TBBPA) with manganese dioxide: kinetics, products, and pathways, Environ. Sci. Technol. 43 (2009) 4480-4486.

[56] P.M. Bastos, J. Eriksson, N. Green, A. Bergman, A standardized method for assessment of oxidative transformations of brominated phenols in water, Chemosphere 70 (2008) 1196-1202.

[57] J.B. Fini, A. Riu, L. Debrauwer, A. Hillenweck, S. Le Mevel, S. Chevolleau, et al., Parallel biotransformation of tetrabromobisphenol A in Xenopus laevis and mammals: Xenopus as a model for endocrine perturbation studies, Toxicol. Sci. 125 (2012) 359-367.

[58] W. Brack, Effect-directed analysis: a promising tool for the identification of organic toxicants in complex mixtures?, Anal. Bioanal. Chem. 377 (2003) 397-407.

[59] E.L. Schymanski, C.M.J. Gallampois, M. Krauss, M. Meringer, S. Neumann, T Schulze, et al., Consensus structure elucidation combining GC/EI-MS, structure generation, and calculated properties, Anal. Chem. 84 (2012) 3287-3295.

[60] Z. Zhang, J.F. Liu, T.T. Feng, Y. Yao, L.H. Gao, G.B. Jiang, Time-resolved fluoroimmunoassay as an advantageous analytical method for assessing the total concentration and environmental risk of fluoroquinolones in surface waters, Environ. Sci. Technol. 47 (2013) 454-462.

[61] Z. Zhang, J.F. Liu, B. Shao, G.B. Jiang, Time-resolved fluoroimmunoassay as an advantageous approach for highly efficient determination of sulfonamides in environmental waters, Environ. Sci. Technol. 44 (2010) 1030-1035. 